\title{
THE DOUBLE-LINED SPECTROSCOPIC BINARY HR 6046
}

\author{
C. D. Scarfe, ${ }^{1}$ R. F. Griffin, ${ }^{2}$ and R. E. M. Griffin ${ }^{3}$
}

\section{RESUMEN}

HR 6046 se conoce desde hace mucho como una binaria espectroscópica de una línea, cuya primaria es de tipo $\mathrm{K}$ tardío. El largo período (de más de seis años) y el alto valor de la función de masa han motivado varios intentos, hasta ahora fallidos, para resolver interferométricamente el sistema. Sin embargo, hemos detectado espectroscópicamente a la secundaria, y presentamos aquí los elementos orbitales espectroscópicos. La secundaria tiene una masa casi igual a la de la primaria, pese a que es mucho más débil. La comparación con espectros estándar para tipos tardíos sugiere que también la secundaria es una estrella evolucionada.

\section{ABSTRACT}

HR 6046 has long been known as a single-lined binary with a late-K-giant primary star. The long period of just over six years and the large mass function led to several, so far unsuccessful, attempts to resolve the system interferometrically. However, we have detected the secondary spectroscopically, and present here the spectroscopic orbital elements. The secondary is nearly as massive as the primary, despite being much fainter. Comparison with late-type standard spectra suggests that it is also an evolved star.

\section{Key Words: BINARIES: SPECTROSCOPIC}

\section{INTRODUCTION}

HR 6046, a bright giant star in Corona Borealis, was found to be a spectroscopic binary by Plaskett et al. (1921). An orbital solution was derived by Christie (1936) from DAO and Mt. Wilson radial velocities, but it was not regarded by Batten (1967) as very reliable.

\section{RADIAL-VELOCITY OBSERVATIONS}

In an effort to obtain an improved orbit, one of us (C.D.S.) began to observe HR 6046 in 1983 with the DAO 1.2-m telescope and radial-velocity spectrometer (Fletcher et al. 1982). But it was not until it was realized that the spectrometer facilitated the detection of companions (Scarfe 1995) that a serious attempt was made to detect such an object in the HR 6046 system. R.F.G. had begun to observe HR 6046 in 1993, and indeed was the first to detect the secondary component, near the periastron passage of 1997. It is much fainter than the primary, as indicated by the weak dip that it contributes to the cross-correlation trace shown in Figure 1. The dotted curves in that figure show the resolution of the trace into dips due to the primary and secondary stars. They were plotted using software developed by R.E.M.G., which is essential for determining reliable radial velocities for blended components. The

\footnotetext{
${ }^{1}$ University of Victoria, BC, Canada. (scarfe@uvic.ca)

${ }^{2}$ University of Cambridge, UK.

${ }^{3}$ Herzberg Institute of Astrophysics, Victoria, BC, Canada.
}

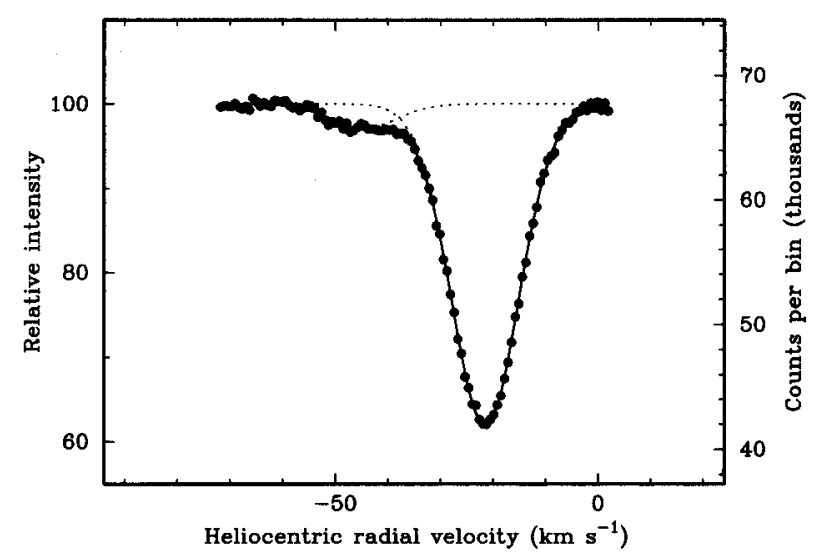

Fig. 1. A spectrometer trace of HR 6046 with the dips due to the two components partially resolved. The dotted curves are fitted to the observed tracing as described in the text.

program uses the instrumental profile as a starting point, and adjusts the depths and, if necessary, the broadening of the individual curves to fit the observed trace.

\section{ORBIT}

Our combined observations now suffice to determine the primary's orbit accurately, and that of the secondary tolerably well. The elements are presented in Table 1, and the velocity curves they represent are drawn through the data in Figure 2. The mass ratio is very close to unity despite the substantial difference in luminosity between the stars. 
TABLE 1

ORBITAL PARAMETERS OF HR 6046

\begin{tabular}{lcc}
\hline Parameter & Value & Uncertainty \\
\hline $\mathrm{P}$ (days) & 2200.7 & 0.4 \\
$\mathrm{~T}(\mathrm{~J} . \mathrm{D})$. & $2,448,559.2$ & 0.7 \\
$\mathrm{~K}_{1}\left(\mathrm{~km} \mathrm{~s}^{-1}\right)$ & 15.44 & 0.06 \\
$\mathrm{~K}_{2}\left(\mathrm{~km} \mathrm{~s}^{-1}\right)$ & 16.02 & 0.29 \\
$\mathrm{e}$ & 0.688 & 0.002 \\
$\omega\left(^{\circ}\right)$ & 9.77 & 0.32 \\
$\gamma\left(\mathrm{km} \mathrm{s}^{-1}\right)$ & -32.13 & 0.03 \\
$a_{1} \sin i(\mathrm{Gm})$ & 339.0 & 1.5 \\
$a_{2} \sin i(\mathrm{Gm})$ & 351.7 & 6.4 \\
$M_{1} \sin ^{3} i\left(M_{\odot}\right)$ & 1.38 & 0.05 \\
$M_{2} \sin ^{3} i\left(M_{\odot}\right)$ & 1.33 & 0.03 \\
$M_{1} / M_{2}$ & 1.038 & 0.019 \\
\hline
\end{tabular}

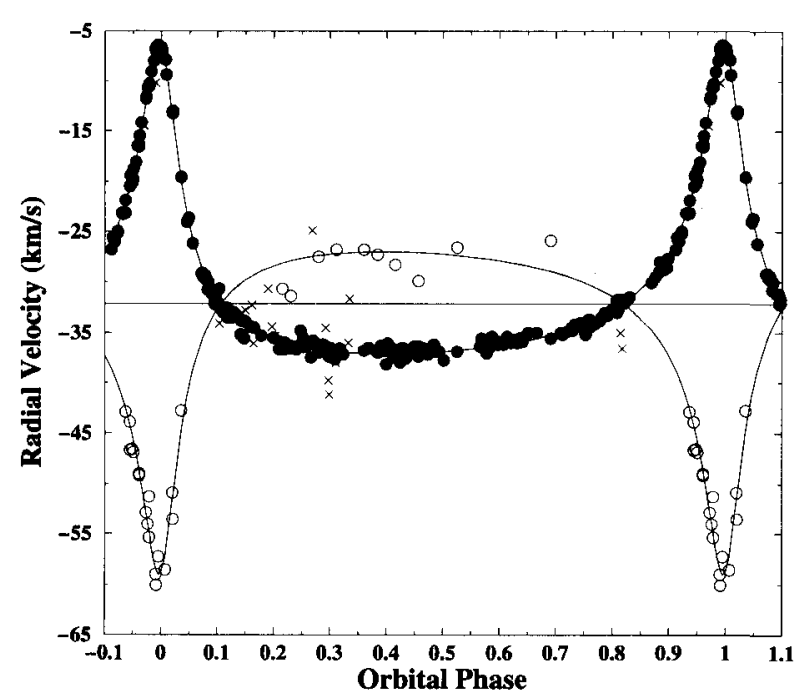

Fig. 2. The radial velocity curves that represent the elements of Table 1, drawn through the data. Solid symbols represent our observations of the primary, and open ones those of the secondary. The crosses represent the data available to Christie.

\section{SPECTROPHOTOMETRY}

In 2001 August R.E.M.G. obtained CCD spectra of HR 6046 at $2.4 \AA \mathrm{mm}^{-1}$ with the DAO $1.2-\mathrm{m}$ telescope. Despite the system's previous classification of

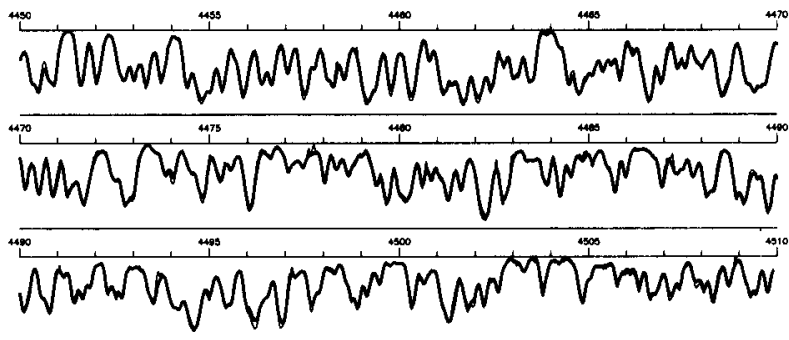

Fig. 3. A tracing of part of the spectrum of HR 6046 (thin line), with the combination of standard M3 II and G7 III spectra superposed (thicker line). Wavelengths in $\AA$ are indicated.

K3 III, the spectrum was best matched by a combination of M3 II and G7 III, as shown in Figure 3. A better match might be achieved with a secondary of luminosity class IV, but no such standard spectrum was available for comparison.

\section{DISCUSSION}

It appears, nevertheless, that the secondary component of HR 6046 has left the main sequence, as might be expected from the primary's advanced evolutionary state and the similarity of the two stars' masses. The primary indeed seems to be near the red giant tip, and the luminosity difference between the components is now perhaps as large as it ever has been. The difficulty that this presents to interferometric observers is made apparent by several reports in the literature of unsuccessful attempts to resolve HR 6046. Nevertheless we encourage further efforts, preferably at short wavelengths. An astrometric orbit would be extremely useful, since it would permit the determination of masses and luminosities for both components of this evolved system.

A more detailed account of this work will be published elsewhere.

\section{REFERENCES}

Batten, A. H. 1967, Publ. Dom. Astrophys. Obs., 13, 119 Christie, W. H. 1936, ApJ, 83, 436

Fletcher, J. M., Harris, H. C., McClure, R. D. \& Scarfe, C. D. 1982, PASP, 94, 1017

Plaskett, J. S., Harper, W. E., Young, R. K. \& Plaskett, H. H. 1921, Publ. Dom. Astrophys. Obs, 2, 3

Scarfe, C. D. 1995, J. Roy. Ast. Soc. of Canada 89, 182 